\title{
Synthesis and self-assembly behavior of amphiphilic diblock copolymer dextran-block-poly( $\varepsilon$-caprolactone) (DEX-b-PCL) in aqueous media
}

\author{
Y. L. Zhang, X. W. Dou, T. Jin* \\ Laboratory of Drug Delivery and Biomaterials, Shanghai Jiao Tong University School of Pharmacy, Shanghai 200240, \\ P. R. China
}

Received 11 April 2010; accepted in revised form 11 June 2010

\begin{abstract}
An amphiphilic diblock copolymer, dextran-block-poly( $\varepsilon$-caprolactone) (DEX- $b$-PCL), with a series of welldefined chain lengths of each block was prepared by conjugating a dextran chain with a PCL block via aza-Michael addition reaction under mild conditions. For the dextran block, samples with relatively uniform molecular weight, 3.5 and $6.0 \mathrm{kDa}$, were used, and the PCL blocks were prepared via ring-opening polymerization at defined ratios of $\varepsilon$-caprolactone to initiator in order to give copolymers with mass fraction of dextran $\left(f_{D E X}\right)$ ranging from 0.16 to 0.45 . When these copolymers were allowed to self-assemble in aqueous solution, the morphology of assembled aggregates varied as a function of $f_{D E X}$ when characterized by transmission electron microscope (TEM), fluorescence microscope (FM) and dynamic laser scattering (DLS). As $f_{D E X}$ decreases gradually from 0.45 to 0.16 , the morphology of the copolymer assembly changes from spherical micelles to worm-like micelles and eventually to polymersomes, together with an increase in particle sizes.
\end{abstract}

Keywords: polymer synthesis, biodegradable polymers, diblock copolymer, self-assembly, mass fraction of the hydrophilic block

\section{Introduction}

Amphiphilic block copolymers have been widely reported to form particulate systems of various morphologies such as spherical or worm-like micelles, polymersomes, large compound micelles, lamellae, and numerous other aggregates [1-8]. Among these morphologies, polymersomes are particularly interesting for their potential applications as carriers of biological therapeutics and diagnostic agents $[9,10]$. Polymersomes differ from polymeric particles and micelles in having a hydrophilic interior to pack biological molecules, and are superior to liposomes for their better mechanical stability and adjustable chemical properties. The thermodynamically stable morphology of block copolymer assemblies is determined by several variables, such as composition and chain length of each block, the ratio of hydrophilic to hydrophobic block, concentrations, as well as solvents, temperatures, additives and so on [11-13]. Among these variables, the chemical nature of diblock copolymers is considered to be the most essential. Discher and Eisenberg have demonstrated that volume fraction of the hydrophilic block $(f)$ is an important factor leading to corresponding time-average shape of the copolymers (e.g. cylinder when $f=0.35 \pm 0.10$, wedge when $f<0.25$ and cone when $f>0.45$ ), and these shapes are critical in determining the morphology of copolymer assemblies as polymersomes, wormlike micelles, or spherical micelles [11, 14]. Their study offered a useful guideline to prepare desired 
nanostructures of poly(ethylene glycol)-blockpoly(lactic acid) (PEG-PLA) copolymers. Although the $f$ range of PEG-PLA may not be applicable to other block copolymers because of their different chemical natures, the demonstrated relationship between fraction of hydrophilic block, molecular shape of copolymer and particle morphology should be universal. Therefore, for each individual block copolymer, scaling relationships between the hydrophilic fraction of copolymer and various aggregate morphologies should be investigated systematically in order to prepare aimed structure of the copolymer.

While PEG has been used as hydrophilic block for most block copolymers to form polymersomes [14-17], it may inhibit bio-macromolecules from being encapsulated into polymersome interior because of its hydrodynamic nature and protein repelling habits (anti-opsonization effect) [18-20]. Because the polymersome interior is limited in space, PEG at the surface of the inner layer is highly crowded and tends to drive macromolecules out of the vesicle interior. It has been reported that the encapsulation efficiency of BSA (bovine serum albumin) into PEG-based polymersomes was only $5 \%$ [21]. To address this problem, using a proteinfriendly hydrophilic block to substitute PEG in the diblock copolymers should be a reasonable approach to improve encapsulation efficiency and protein stability. In the present study, we selected dextran as the hydrophilic segment to prepare an amphiphilic diblock polymer. Dextran is widely used as blood substitution, drug carriers and aqueous phase material for protein purification because its definite biocompatibility, biodegradability, hydrophilicity and high affinity to bio-macromolecules [22, 23]. In addition, dextran possesses multiple hydroxyls which are convenient for chemical modification to endow polymersome surfaces with various desired functions such as drug-targeting and diagnostic recognition. In addition, poly( $\varepsilon$-caprolactone) (PCL) was chosen as the hydrophobic block of the amphiphilic copolymer for its well demonstrated biocompatibility, biodegradability, and wide utilization as a drug delivery material [24, 25]. However, there are limited studies regarding block copolymers with dextran as hydrophilic segment so far. Houga et al. [26] have reported self-assembly of dextran-block-polystyrene (DEX-b-PS) into micelles and polymersomes. Liu and co-workers have prepared a dextran-PCL block copolymer and studied its micellar characteristics [27]. A study on the polymersomes prepared by dextran-blockpoly( $\gamma$-benzyl-L-glutamate) was carried out by Schatz et al. [28]. Hernandez et al. [29] have synthesized double hydrophilic block copolymers of carboxymethyl dextran-block-poly(ethylene glycol) (CMD-PEG) and studied their self-assembly behavior as a function of solution $\mathrm{pH}$. Yang et al. [30] also prepared double hydrophilic diblock copolymer of hyaluronan-block-poly(2-ethyl-2oxazoline) via terminal reductive amination. Very recently, Sun and his co-workers prepared disulfide-linked dextran- $b$-poly( $\varepsilon$-caprolactone) diblock copolymer (DEX-SS-PCL) copolymer and selfassembled into micelles with a diameter of about $60 \mathrm{~nm}$ [31]. To the best of our knowledge, there has not yet been a report describing polymersomes formed by dextran- $b$-PCL block copolymers.

According to literature methods, the synthetic strategies for saccharide-terminated polymers can mainly be classified into two approaches. The first approach is based on end to end coupling strategy via reductive amination or aza-Michael addition [27, 32-34]. The second approach is that the saccharides are first derivatized into macro-initiators and then initiate the controlled or living polymerization of monomers [26, 35]. The latter synthetic procedure requires several steps, including tedious protecting-deprotecting steps. Furthermore, if the hydroxyl groups on the backbone of the saccharides are not protected completely, comb-like grafted copolymers other than diblock copolymers would be obtained. For the end to end conjugation of dextran and PCL blocks, a pioneering work has been performed by Liu et al. [27] who coupled an amino-functionalized dextran to acryloyl-functionalized PCL with the catalyst of p-methylbenzene sulfonic acid at $120^{\circ} \mathrm{C}$ for $8 \mathrm{~h}$. However, Moreau has indicated that high temperatures such as above $100^{\circ} \mathrm{C}$ are not appropriate for dextran because it could be degraded [36]. Therefore, the reaction conditions should be selected carefully to avoid degradation of reaction precursors. Because maleimide possesses two carbonyl groups conjugated to the double bond, presenting a highly electronegative property and more susceptible to reaction with nucleophiles [37], it is proved to be an appropriate reactive group in Michael addition under mild conditions $[34,38]$. We report herein a 
mild and simplified route to synthesize the copolymer DEX- $b$-PCL, in which the precursors maleimide-terminated PCL and amino-terminated dextran were synthesized previously, followed by an end to end coupling via aza-Michael addition reaction.

In this paper, using the rationally synthesized DEX$b$-PCL, we investigated the self-assembly behaviors of this amphiphilic diblock copolymer as a function of the structural parameters of the block copolymer. The relationship of the hydrophilic mass fractions of DEX-b-PCL copolymers $\left(f_{D E X}\right)$ with their self-assembled morphologies in aqueous medium is addressed. Based on our own experiences, a predetermined $f_{D E X}$ range within 0.16 to 0.45 was selected to cover all the three morphological forms of block copolymer assemblies. When the mass fraction of the hydrophilic chain decreases from 0.45 to 0.16 , the morphological form of the copolymer assemblies vary from spherical micelles, worm-like micelles, nano-sized polymersomes to giant polymersomes accordingly.

\section{Experimental}

\subsection{Materials}

$\varepsilon$-Caprolactone ( $\varepsilon$-CL) $(99 \%)$ was supplied by Sigma-Aldrich, Inc. Shanghai, China. Prior to use, the $\varepsilon$-CL was dried over $\mathrm{CaH}_{2}$ for $48 \mathrm{~h}$ and distilled under reduced pressure. Dextran T3.5 $\left(M_{w}\right.$ $3500 \mathrm{~g} \cdot \mathrm{mol}^{-1}$, polydispersity index, i.e. PDI 1.5) and T6 $\left(M_{w} 6000 \mathrm{~g} \cdot \mathrm{mol}^{-1}\right.$, PDI 1.5) were purchased from Pharmacosmos A/S, Holbaek, Denmark. Stannous octoate (95\%), $\mathrm{Sn}(\mathrm{Oct})_{2}$, was supplied by Sigma-Aldrich, Inc. Shanghai, China. Sodium cyanoborohydride $\left(\mathrm{NaCNBH}_{3}, 97 \%\right)$ was purchased from Alfa Aesar, TianJin, China. Nhydroxyethyl maleimide (HEMI) was synthesized according to the literature procedures $[39,40]$. The toluene and dimethyl sulfoxide (DMSO) (analytical grade, provided by Sinopharm Chemical Reagent Co., Shanghai, China) were first dried over $\mathrm{CaCl}_{2}$ and $\mathrm{CaH}_{2}$, respectively, and then distilled prior to use. All other reagents were analytical grade and used as received.

\subsection{Synthesis of HEMI-PCL}

The poly( $\varepsilon$-caprolactone) end-capped with $\mathrm{N}$ hydroxyethyl maleimide (HEMI-PCL) was pre- pared by ring opening polymerization of $\varepsilon$-caprolactone using N-hydroxyethyl maleimide as the initiator and $\mathrm{Sn}(\mathrm{Oct})_{2}$ as a catalyst. Briefly, a predetermined amount of HEMI was introduced into a $150 \mathrm{ml}$ three-necked flask connected to a vacuum/ nitrogen line. After three times of nitrogen purge, $5.0 \mathrm{~g}$ \&-caprolactone $(43.8 \mathrm{mmol}), 0.017 \mathrm{~g} \mathrm{Sn}(\mathrm{Oct})_{2}$ $(0.043 \mathrm{mmol})$ were dissolved in $30 \mathrm{ml}$ toluene and injected into the flask under nitrogen atmosphere and allowed to react under magnetic stirring at $120^{\circ} \mathrm{C}$ for 15 hours. Molecular weight of HEMIPCL was determined by the molar ratio of $\varepsilon$-caprolactone to HEMI. The reaction was then terminated by cooling the reactants down to room temperature, followed by precipitating the product in methanol. The obtained HEMI-PCL was further purified by three additional cycles of solubilization (in chloroform) and precipitation (in methanol). Finally, the obtained product was dried at room temperature under vacuum for $48 \mathrm{~h}$.

${ }^{1} \mathrm{H} \mathrm{NMR}\left(\mathrm{CDCl}_{3} 300 \mathrm{MHz}\right)$ :

$\delta=6.74(\mathrm{~s}, 2 \mathrm{H},-\mathrm{C} \underline{\mathrm{H}}=\mathrm{C} \underline{\mathrm{H}}-)$,

4.24 (t, 2H, $-\mathrm{N}-\mathrm{CH}_{2}-\mathrm{C}_{2}-\mathrm{O}-$ ),

4.07 (t, 2H, $-\mathrm{CH}_{2}-\mathrm{O}-\mathrm{C}(\mathrm{O})-$ ),

$3.80\left(\mathrm{t}, 2 \mathrm{H},-\mathrm{N}-\mathrm{C}_{2}-\right.$ ),

3.65 (t, $\left.2 \mathrm{H},-\mathrm{C}_{2}-\mathrm{OH}\right), 2.31$ (t, $2 \mathrm{H},-\mathrm{C}(\mathrm{O})-\mathrm{C}_{2}-$ ),

1.71-1.61 (m, 4H, $-\mathrm{CH}_{2}-\mathrm{C}_{2}-\mathrm{CH}_{2}-\mathrm{C}_{2}-\mathrm{CH}_{2}-\mathrm{O}-$ ),

1.44-1.34 (m, 2H, $-\mathrm{CH}_{2}-\mathrm{CH}_{2}-\mathrm{CH}_{2}-\mathrm{CH}_{2}-\mathrm{CH}_{2}-\mathrm{O}-$ ).

\subsection{Synthesis of EDA-DEX}

The 1,2-ethylenediamine-terminated dextran (EDADEX) was prepared by terminal reductive amination reaction with sodium cyanoborohydride $\left(\mathrm{NaCNBH}_{3}\right)$ as reducing agent according to Figure 1. Briefly, $20 \mathrm{mg}$ of $\mathrm{NaCNBH}_{3}$ was added into a $50 \mathrm{ml}$ DMSO solution containing $5.0 \mathrm{~g}$ dextran and excess of 1,2-ethylenediamine (10-fold molar excess over dextran). The reactant mixture was stirred at $60^{\circ} \mathrm{C}$ for 7 days, and additional $\mathrm{NaCNBH}_{3}$ (20 mg) was added each day. Then the reaction was terminated by cooling the reactants to room temperature, followed by pouring the mixture into methanol to precipitate. The product was then purified by three cycles of dissolving (in water) and precipitating (in methanol) treatment, and finally lyophilized prior to storage.

${ }^{1} \mathrm{H}$ NMR (DMSO-d $6300 \mathrm{MHz}$ ):

$\delta=4.67(\mathrm{~s}, 1 \mathrm{H}$, anomeric $\mathrm{H})$, 


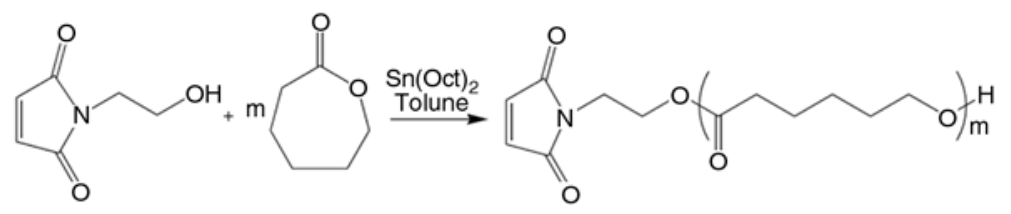

a)

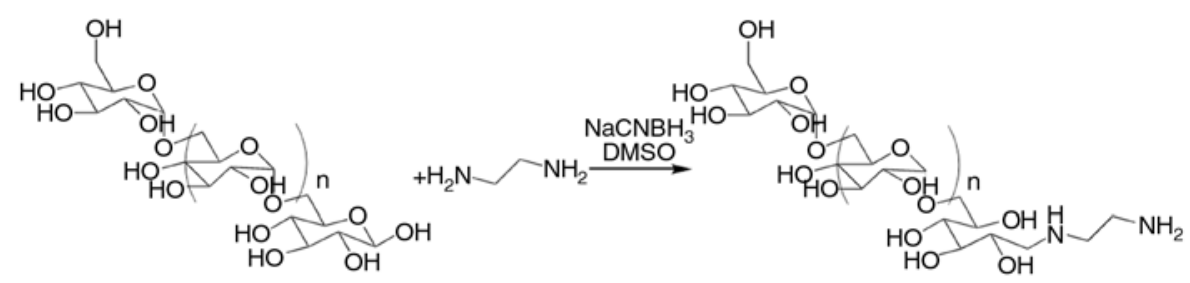

b)

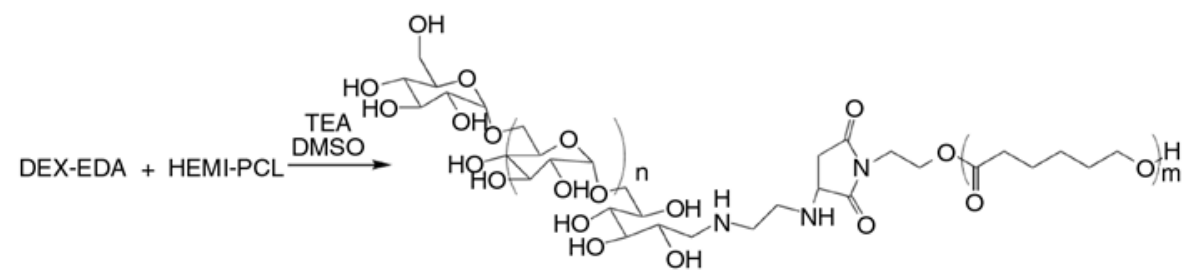

c)

Figure 1. Synthetic route for amphiphilic diblock copolymer DEX- $b$-PCL

3.0-3.8 ( $\mathrm{m}, 5 \mathrm{H}$, glycosidic $\mathrm{H})$,

$2.92\left(\mathrm{~m}, 4 \mathrm{H},-\mathrm{NH}-\mathrm{C}_{2}-\mathrm{C}_{2}-\mathrm{NH}_{2}\right)$.

\subsection{Synthesis of DEX-b-PCL}

The dextran-block-poly ( $\varepsilon$-caprolactone) (DEX- $b$ PCL) copolymers were prepared by end-to-end conjugation of the EDA-DEX and HEMI-PCL via aza-Michael addition described as Figure 1. HEMIPCL $(1.0 \mathrm{~g})$ and extra amount of EDA-DEX (2 molar equivalents of HEMI-PCL) as well as catalytic amount of triethylamine (TEA) were dissolved in $20 \mathrm{ml}$ DMSO and kept in a round-bottom flask. The reaction was performed under magnetic stirring at $70^{\circ} \mathrm{C}$ for $48 \mathrm{~h}$. Then the reaction mixture was cooled to room temperature and DMSO was removed by evaporation under a reduced pressure. The resulting product was purified by washing with small amount of water to remove un-reacted EDADEX, then with tetrahydrofuran (THF) to remove the un-reacted HEMI-PCL. The obtained product was converted to white powder after lyophilization. ${ }^{1} \mathrm{H}$ NMR (DMSO-d $6300 \mathrm{MHz}$ ):

$\delta=4.92\left(\mathrm{~s}, 1 \mathrm{H}\right.$, glycosidic $\left.-\mathrm{C}_{4}-\mathrm{OH}\right)$,

4.86 (s, $1 \mathrm{H}$, glycosidic- $\left.\mathrm{C}_{3}-\mathrm{O} \underline{\mathrm{H}}\right)$,

4.65 (s, 1H, anomeric $\mathrm{H})$,

4.51 (s, $1 \mathrm{H}$, glycosidic- $\left.\mathrm{C}_{2}-\mathrm{OH}\right)$,

3.96 (t, 2H, $-\mathrm{C}_{2}-\mathrm{O}-$ ),

3.0-3.8 ( $\mathrm{m}, 5 \mathrm{H}$, glycosidic $\mathrm{H})$, $2.45\left(\mathrm{t}, 2 \mathrm{H},-\mathrm{C}(\mathrm{O})-\mathrm{C}_{2}-\right)$,

1.50 (m, $\left.4 \mathrm{H},-\mathrm{CH}_{2}-\mathrm{C}_{2}-\mathrm{CH}_{2}-\mathrm{CH}_{2}-\mathrm{CH}_{2}-\mathrm{O}-\right)$,

1.27 (m, $2 \mathrm{H},-\mathrm{CH}_{2}-\mathrm{CH}_{2}-\mathrm{CH}_{2}-\mathrm{CH}_{2}-\mathrm{CH}_{2}-\mathrm{O}-$ ).

\subsection{Self-assembly of DEX- $b$-PCL}

The block copolymer, DEX- $b$-PCL, of given dextran fraction was added in aqueous media at a concentration of $0.5 \mathrm{mg} \cdot \mathrm{ml}^{-1}$, followed by vortex for dispersion. The resulted suspension was then incubated at $60^{\circ} \mathrm{C}$ for $12-48 \mathrm{~h}$. The morphology of the particulates formed from the block copolymer was characterized by TEM and DLS.

\subsection{Characterization}

\subsection{1. ${ }^{1}$ H NMR}

Proton nuclear magnetic resonance ( ${ }^{1} \mathrm{H}$ NMR) spectra of the polymers were recorded on a NMR Spectrometer (ARX-300, Bruker, Switzerland) operating at $300 \mathrm{MHz}$ at $25^{\circ} \mathrm{C}$. Deuterated chloroform $\left(\mathrm{CDCl}_{3}\right)$ and dimethyl sulfoxide- $\mathrm{d}_{6}$ (DMSO$\mathrm{d}_{6}$ ) were used as solvents.

\subsubsection{GPC}

Gel permeation chromatography (GPC) measurements were performed using a Waters HPLC system equipped with a Waters 410 refractive index 
(RI) detector, a Waters 515 HPLC pump (Waters, Milford, MA, USA) and a Waters ultra-styragel column $(5 \mu \mathrm{m})$ at $40^{\circ} \mathrm{C}$. The sample, $20 \mu \mathrm{l}$ in volume, was injected to the system and eluted with dimethylformamide mobile phase containing $0.1 \%$ lithium bromide at a flow rate of $1.0 \mathrm{ml} \mathrm{min}^{-1}$. The calibration of molecular weight was carried out using polystyrene as standard.

\subsubsection{TEM}

The transmission electron microscopic (TEM) images were taken using an electron microscope system (JEM2010, JEOL, Japan) at an acceleration voltage of $120 \mathrm{kV}$. TEM samples were prepared by placing one drop of the aggregate suspension onto a copper mesh covered with carbon film. After $1 \mathrm{~h}$, the excess solution was removed with a filter paper followed by negative staining with $2 \%$ [w/v] phosphotungstic acid solution ( $\mathrm{pH} 7.0$ ) for $30 \mathrm{~s}$. For some samples, the staining treatment was omitted.

\subsubsection{FM}

The fluorescence microscopic (FM) images of the self-assembled particulate samples were taken using an inverted microscope (Olympus IX71, Olympus Optical Co. Ltd, Tokyo, Japan) equipped with 10X, 20X, 40X UPlanFL objectives, a 100w mercury bulb and a DP 70 color CCD camera, as well as Olympus DP capture software.

\subsubsection{DLS}

Dynamic laser scattering (DLS) measurements were performed using a 90 Plus/BI-MAS particle size analyzer (90 Plus/BI-MAS, Brookhaven Instruments Corporation, USA). The samples of selfassembled diblock copolymers were suspended in $0.01 \mathrm{M}$ phosphate buffer solution (PBS, $\mathrm{pH}$ 7.4) at the concentration of $0.5 \mathrm{mg} \cdot \mathrm{ml}^{-1}$ prior to measurements. Hydrodynamic radius $R_{h}$ of the particles was calculated based on three repeated measurements.

\section{Results and discussion}

\subsection{Preparation of amphiphilic diblock copolymers}

The amphiphilic diblock copolymers DEX- $b$-PCL were successfully prepared by combination technologies of ROP, a reductive amination reaction and an aza-Michael addition according to Figure 1. The characteristics of the diblock copolymers and their precursors were determined by ${ }^{1} \mathrm{H}$ NMR, GPC analysis and the results were summarized in Table 1 and Table 2. In order to obtain diblock copolymers DEX- $b$-PCL with various $f_{D E X}$, two precursors, HEMI-PCL and EDA-DEX, of different chain

Table 1. Synthesis and characterization of HEMI-PCL by ROP

\begin{tabular}{|c|c|c|c|c|c|c|}
\hline Polymer samplea & $\mathbf{M} / \mathbf{I}^{\mathbf{b}}$ & DPc & $\mathrm{M}_{\mathrm{n}}{ }^{\mathrm{d}}[\mathrm{g} / \mathrm{mol}]$ & $\mathrm{M}_{\mathrm{n}}^{\mathrm{e}}[\mathrm{g} / \mathrm{mol}]$ & PDIe & Yieldf [\%] \\
\hline HEMI-PCL $_{7.5 k}$ & 65 & 66 & 7500 & 12000 & 1.12 & 92 \\
\hline HEMI-PCL9.2k & 80 & 80 & 9200 & 13200 & 1.15 & 89 \\
\hline HEMI-PCL $_{11.9 k}$ & 100 & 105 & 11900 & 18400 & 1.14 & 94 \\
\hline HEMI-PCL $18.9 k$ & 165 & 166 & 18900 & 23400 & 1.19 & 90 \\
\hline
\end{tabular}

aThe polymerization was catalyzed by $\mathrm{Sn}(\mathrm{Oct})_{2}$ in toluene at $120^{\circ} \mathrm{C}$ for $15 \mathrm{~h}$;

${ }^{b}$ Molar ratio of monomer to initiator; ${ }^{\mathrm{D} D P}$ was calculated from ${ }^{1} \mathrm{H}$ NMR spectroscopy; ${ }^{\mathrm{d}} M_{n}$ was determined by ${ }^{1} \mathrm{H}$ NMR spectroscopy;

${ }^{\mathrm{e}} M_{n}$ and PDI were determined by GPC analysis with linear polystyrene as standards; fYields were determined by gravimetry

Table 2. Synthesis and characterization of amphiphilic diblock copolymers DEX- $b$-PCL

\begin{tabular}{|c|c|c|c|c|c|c|}
\hline Polymer sample ${ }^{a}$ & EDA-DEX $^{\mathbf{a}}$ & HEMI-PCL ${ }^{a}$ & 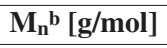 & PDI $^{b}$ & $f_{\mathrm{DEX}} \mathrm{c}^{\mathrm{c}}$ & Yield $^{d}[\%]$ \\
\hline $\mathrm{DEX}_{6.0 k}-b-\mathrm{PCL}_{7.5 k}$ & T6 & HEMI-PCL $7.5 k$ & 17500 & 1.74 & 0.45 & 37 \\
\hline $\mathrm{DEX}_{6.0 k}-b-\mathrm{PCL}_{9.2 k}$ & T6 & HEMI-PCL $9.2 k$ & 20600 & 2.08 & 0.40 & 63 \\
\hline $\mathrm{DEX}_{3.5 k-b-\mathrm{PCL}_{7.5 k}}$ & T3.5 & HEMI-PCL $7.5 k$ & 17800 & 2.04 & 0.32 & 44 \\
\hline $\mathrm{DEX}_{3.5 k}-b$-PCL $9.2 k$ & $\mathrm{~T} 3.5$ & HEMI-PCL $9.2 k$ & 18600 & 1.89 & 0.28 & 57 \\
\hline $\mathrm{DEX}_{3.5 k-b-\mathrm{PCL}_{11.9 k}}$ & $\mathrm{~T} 3.5$ & HEMI-PCL $11.9 k$ & 24200 & 2.12 & 0.23 & 71 \\
\hline $\mathrm{DEX}_{3.5 k}-b-\mathrm{PCL}_{18.9 k}$ & $\mathrm{~T} 3.5$ & HEMI-PCL $_{18.9 k}$ & 31400 & 2.01 & 0.16 & 46 \\
\hline
\end{tabular}

aAza-Michael addition was carried out in DMSO at $70^{\circ} \mathrm{C}$ for $48 \mathrm{~h}$;

${ }^{\mathrm{b}} M_{n}$ and PDI were determined by GPC analysis with linear polystyrene as standards;

cThe dextran mass fraction $\left(f_{D E X}\right)$ was calculated by the molecular weight of dextran block divided by the molecular weight of DEX- $b$-PCL;

dYields were determined by gravimetry 
lengths were prepared firstly. For HEMI-PCL, desired chain length was attained by adjusting the ratio of $\varepsilon$-caprolactone to the initiator of HEMI. For EDA-DEX, dextran of two defined molecular weights, 3.5 and $6.0 \mathrm{kDa}$ were used in terminal hydroxyl activation. The ${ }^{1} \mathrm{H}$ NMR spectra in Figure 2 represents one of the copolymers $\mathrm{DEX}_{3.5 k^{-}} b-$
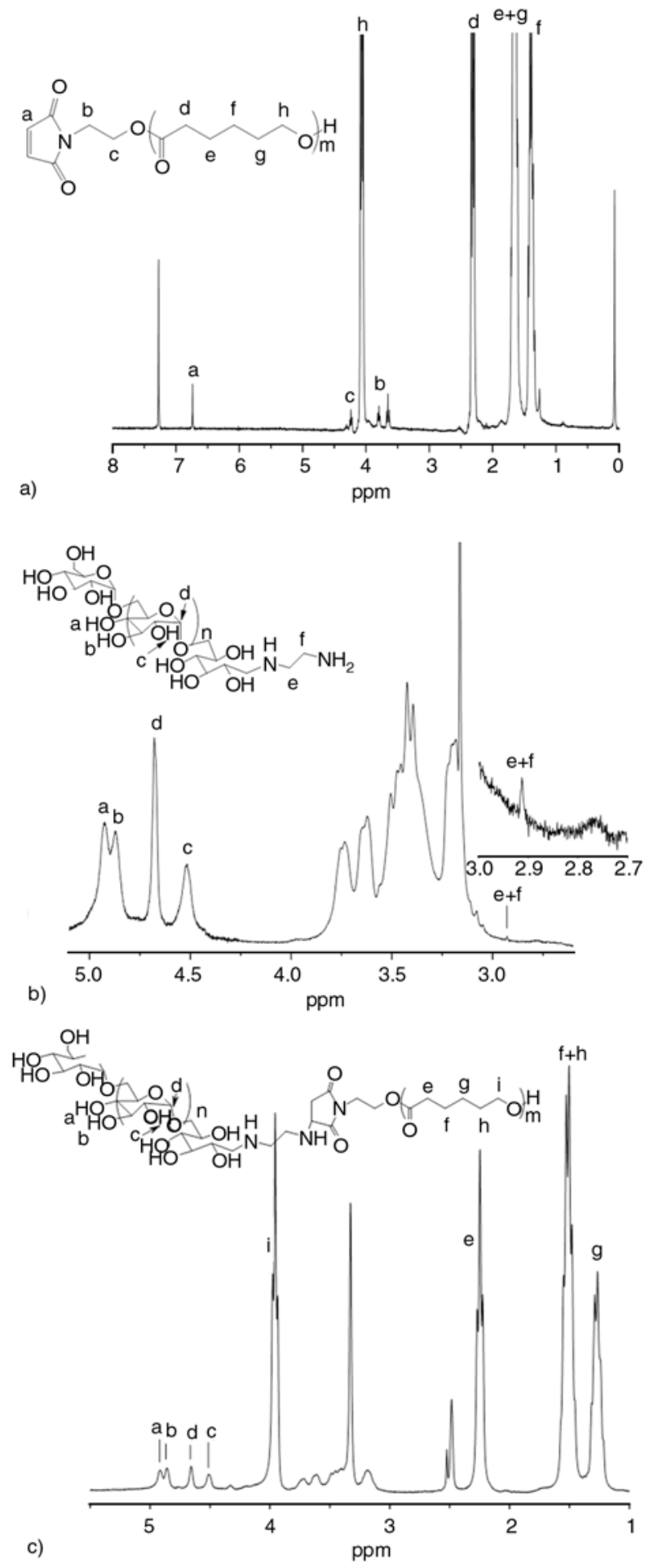

Figure 2. ${ }^{1} \mathrm{H}$ NMR spectra of (a) HEMI-PCL9.2k (solvent $\mathrm{CDCl}_{3}$ ), (b) EDA-DEX ${ }_{3.5 k}$ (solvent DMSO-d 6 ) and (c) DEX $_{3.5 k}-b$-PCL9.2k (solvent DMSO-d 6 )
PCL $9.2 k$, in which the molecular weight of PCL chain is $9.2 \mathrm{kDa}$ ( $\varepsilon$-caprolactone/HEMI $=80 / 1$ ) and the molecular weight of dextran chain is $3.5 \mathrm{kDa}$.

The chemical shifts at $6.74,4.07$ and $2.31 \mathrm{ppm}$ in the ${ }^{1} \mathrm{H}$ NMR spectrum of HEMI-PCL (Figure 2a) are attributed to the characteristic proton signals of $-\mathrm{C} \underline{\mathrm{H}}=\mathrm{C} \underline{\mathrm{H}}-,-\mathrm{C}_{2}-\mathrm{O}-\mathrm{C}(\mathrm{O})-$ and $-\mathrm{C}(\mathrm{O})-\mathrm{C}_{2}-$, respectively. The chemical shifts of the alkane protons, $-\mathrm{C}-\mathrm{C}_{2} \underline{\mathrm{C}}_{2} \underline{\mathrm{C}}_{2}-\mathrm{C}-$, are below $2.0 \mathrm{ppm}$. All the expected peaks from HEMI and PCL have been identified in the ${ }^{1} \mathrm{H}$ NMR spectrum shown in Figure $2 \mathrm{a}$, indicating that the expected HEMI-PCL was formed. The degree of polymerization (DP) of the polymer is calculated from the ratio of the ${ }^{1} \mathrm{H}$ NMR peak areas at $\delta=2.31 \mathrm{ppm}$ to that at $\delta=$ $6.74 \mathrm{ppm}$. The results are listed in Table 1 . These ratios are in agreement with the feed ratio of $\varepsilon$-CL to HEMI in reactants, indicating a high conversion. The polydispersity indices (PDI) of HEMI-PCL measured by GPC are listed in Table 1, which shows a narrow distribution in the range of 1.12-1.19. Therefore, the HEMI-PCL blocks of various chain lengths were successfully synthesized.

The formation of EDA-DEX, an amino-terminated dextran, was confirmed by the ${ }^{1} \mathrm{H}$ NMR spectrum shown in Figure 2b. The characteristic anomeric hydrogen of each dextran ring $(-\mathrm{O}-\mathrm{C} \underline{\mathrm{H}}-\mathrm{O}-)$ is assigned to the chemical shift at $\delta=4.67 \mathrm{ppm}$ (peak d), and the chemical shifts of the hydroxyl protons of dextran are divided to two groups at 4.87-4.92 ppm (peak a, b) and 4.52 ppm (peak c), respectively. The weak resonance peak (peak e+f) at $\delta=2.92 \mathrm{ppm}$ is assigned to the methylene protons of ethylenediamine conjugated to the end of dextran, indicating the terminal reductive amination was reacted successfully. However, since the peak $\mathrm{e}+\mathrm{f}$ is considerably less intensive as compared with those of the dextran sugar ring, we presume that amination of dextran was incomplete. The calculated conversion of dextran to EDA-DEX is approximately $15-31 \%$, which was used to set up the next step of synthesis, conjugation of EDADEX with HEMI-PCL. There were extra amount of EDA-DEX (with consideration of un-conjugated dextran) in the reaction system to ensure sufficient yield of DEX- $b$-PCL. Un-conjugated dextran itself does not react with HEMI-PCL and could be removed in the purification process. The reasons for the limited conversion may be that only $0.024 \%$ of the terminal hydroxyls in dextran take the reac- 
tive free aldehyde form in a neutral solution under equilibrium due to the mutarotation phenomenon [22], and that the imine formation is a reversible and slow reaction which limited the overall reaction rate [41].

The last step of DEX-b-PCL synthesis, azaMichael addition between the amino group at the end of EDA-DEX block and the maleimide group at the end of HEMI-PCL block, was rather straightforward. The reaction proceeded with EDA-DEX in extra at $70^{\circ} \mathrm{C}$ for $48 \mathrm{~h}$ under catalysis by TEA. Figure $2 \mathrm{c}$ shows the ${ }^{1} \mathrm{H}$ NMR spectrum of a block copolymer with given chain lengths, $\mathrm{DEX}_{3.5 k}-b$ PCL $9.2 k$. Both the peaks of PCL segment at 3.96, $2.45,1.50,1.27 \mathrm{ppm}$ and those of dextran segment at $4.92,4.86,4.65,3.0-3.8 \mathrm{ppm}$ are identified. Moreover, the chemical shift of the maleimido protons at $\delta=6.80 \mathrm{ppm}$ completely disappeared, indicating that the maleimido $\mathrm{C}=\mathrm{C}$ double bonds of HEMI-PCL were all conjugated with the primary amine of EDA-DEX. These results verify the successful conjugation of EDA-DEX to the HEMIPCL.

Based on these GPC curves of the DEX- $b$-PCL diblock copolymers (Figure 3), weight-average molecular weight $\left(M_{w}\right)$ and number-average molecular weight $\left(M_{n}\right)$ and polydispersity index (PDI) for each of the copolymers were obtained and summarized in Table 2 . When the $f_{D E X}$ of diblock copolymers decreased from 0.45 to 0.16 , the curves gradually shift to a higher molecular weight region, and the peaks of DEX segment in NMR spectrum steadily decreased compared to those of PCL seg-

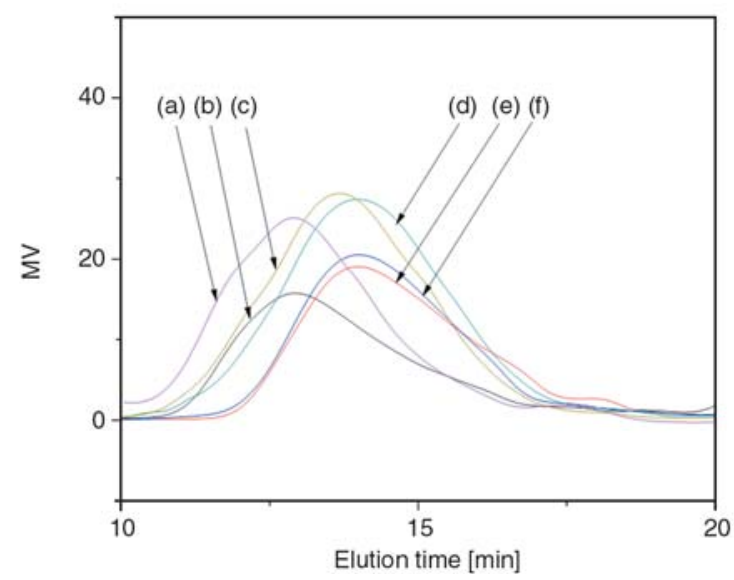

Figure 3. GPC curves of DEX- $b$-PCL diblock copolymers. (a) $\mathrm{DEX}_{3.5 k}-b$-PCL $18.9 k$, (b) $\mathrm{DEX}_{3.5 k}-b$ $\mathrm{PCL}_{11.9 k}$, (c) $\mathrm{DEX}_{6.0 k}-b$-PCL9.2k,

(d) $\mathrm{DEX}_{3.5 k}-b$-PCL $9.2 k$, (e) $\mathrm{DEX}_{3.5 k}-b$-PCL $7.5 k$,

(f) $\mathrm{DEX}_{6.0 k}-b-\mathrm{PCL}_{7.5 k}$ ment. In addition, the yield of the DEX- $b$-PCL product ranging from 37 to $71 \%$ is relatively low, which is probably due to the three times of purification with water. During this process, the excess dextran was removed but part of the DEX- $b$-PCL product may also be removed, especially for the copolymers with high $f_{D E X}$ and thus with relatively large solubility in water. The lowest yield of the $\operatorname{DEX}_{6.0 k}-b-P L_{7.5 k}$ may be attributed to its highest $f_{D E X}$.

\subsection{Self-assembly of the amphiphilic diblock copolymers}

We investigated the self-assembly of amphiphilic diblock copolymers DEX- $b$-PCL with different ratios of hydrophilic to hydrophobic block lengths in neutral aqueous solutions. It was shown, in previous studies, that micelles were made from dextran-PCL copolymer with $f_{D E X}=0.57$ [27] and dextran-SS-PCL copolymer with $f_{D E X}=0.66$ by solvent exchange method [31]. Based on the general empirical law proposed by Discher and Ahmed $[11,14]$, further decreasing the $f_{D E X}$ of diblock copolymers might result in the formation of vesicles or inverted nanostructures. Therefore, in this study, a series of diblock copolymers with $f_{D E X}$ in the range of 0.16 to 0.45 were used to investigate the effect of the relative hydrophilic block lengths on their self-assembly behaviors. All self-assembled aggregates in the study were prepared in PBS solution ( $\mathrm{pH} 7.4,0.01 \mathrm{M}$ ) by bulk hydration method, and the solution samples at a concentration of $0.5 \mathrm{mg} \cdot \mathrm{ml}^{-1}$ were analyzed by TEM. For given dextran chain length, smaller $f_{D E X}$ means larger hydrophobic block as well as larger overall molecular weight of the copolymer.

Figure 4 shows that the morphological forms of the block copolymers, DEX- $b$-PCL, change from spherical micelles, worm-like micelles to polymersomes by varying $f_{D E X}$ from 0.45 to 0.16 correspondingly. At a high $f_{D E X}(0.45)$, the copolymer $\left(\mathrm{DEX}_{6.0 k}-b-\mathrm{PCL}_{7.5 k}\right)$ formed spherical micelles with diameters of $25 \pm 5 \mathrm{~nm}$ (Figure $4 \mathrm{a}$, samples were not stained). As $f_{D E X}$ decreased to the range of 0.40 and 0.32 (DEX $6.0 k-b$-PCL9.2k and DEX $_{3.5 k}-b-$ $\mathrm{PCL}_{7.5 k}$ ), worm-shaped micelles were formed together with spherical micelles (Figure 4b). The size of spherical micelles formed from $\mathrm{DEX}_{3.5 k}-b$ $\mathrm{PCL}_{7.5 k}\left(f_{D E X}=0.32\right)$ was larger than those from 

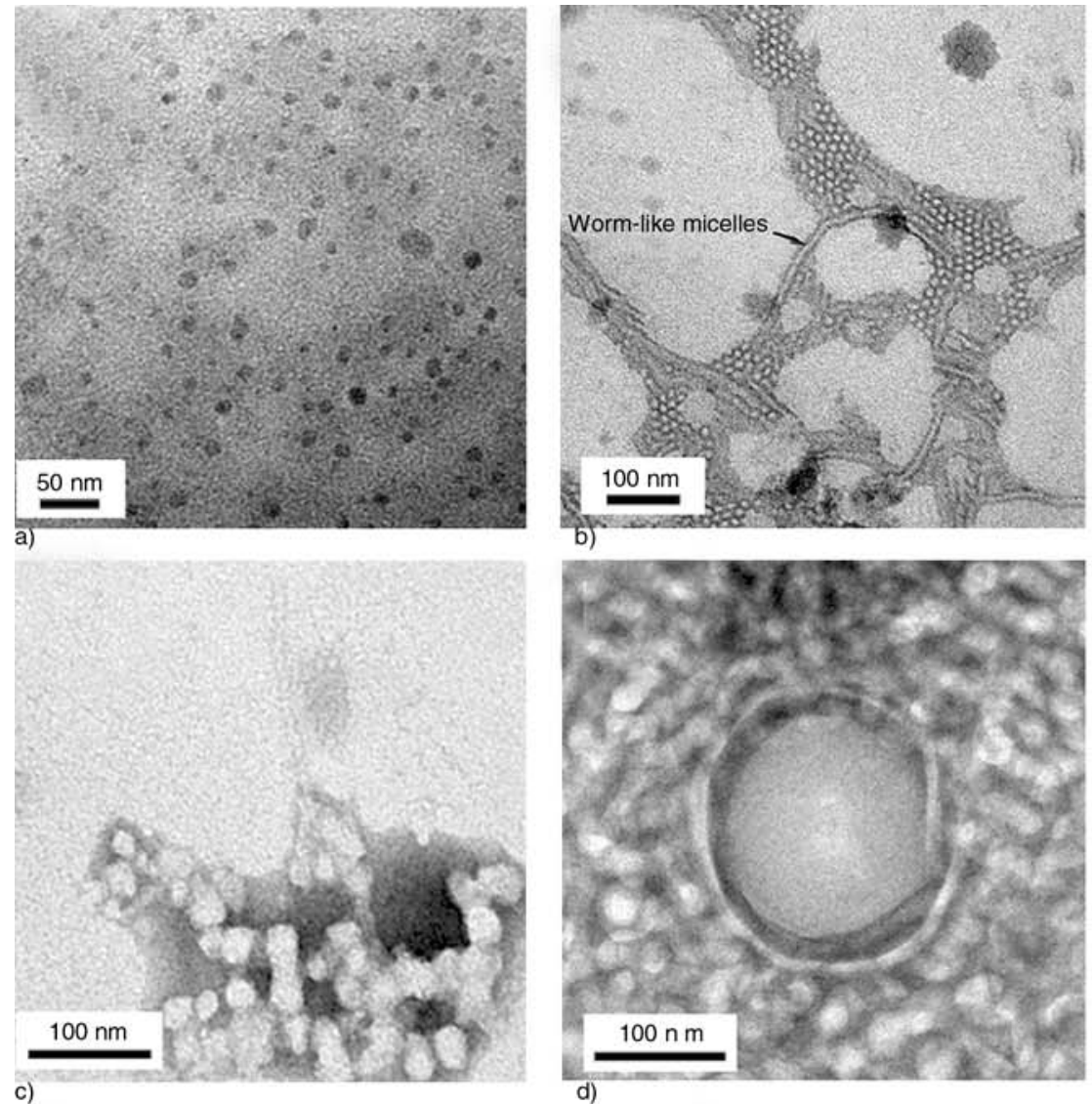

c)
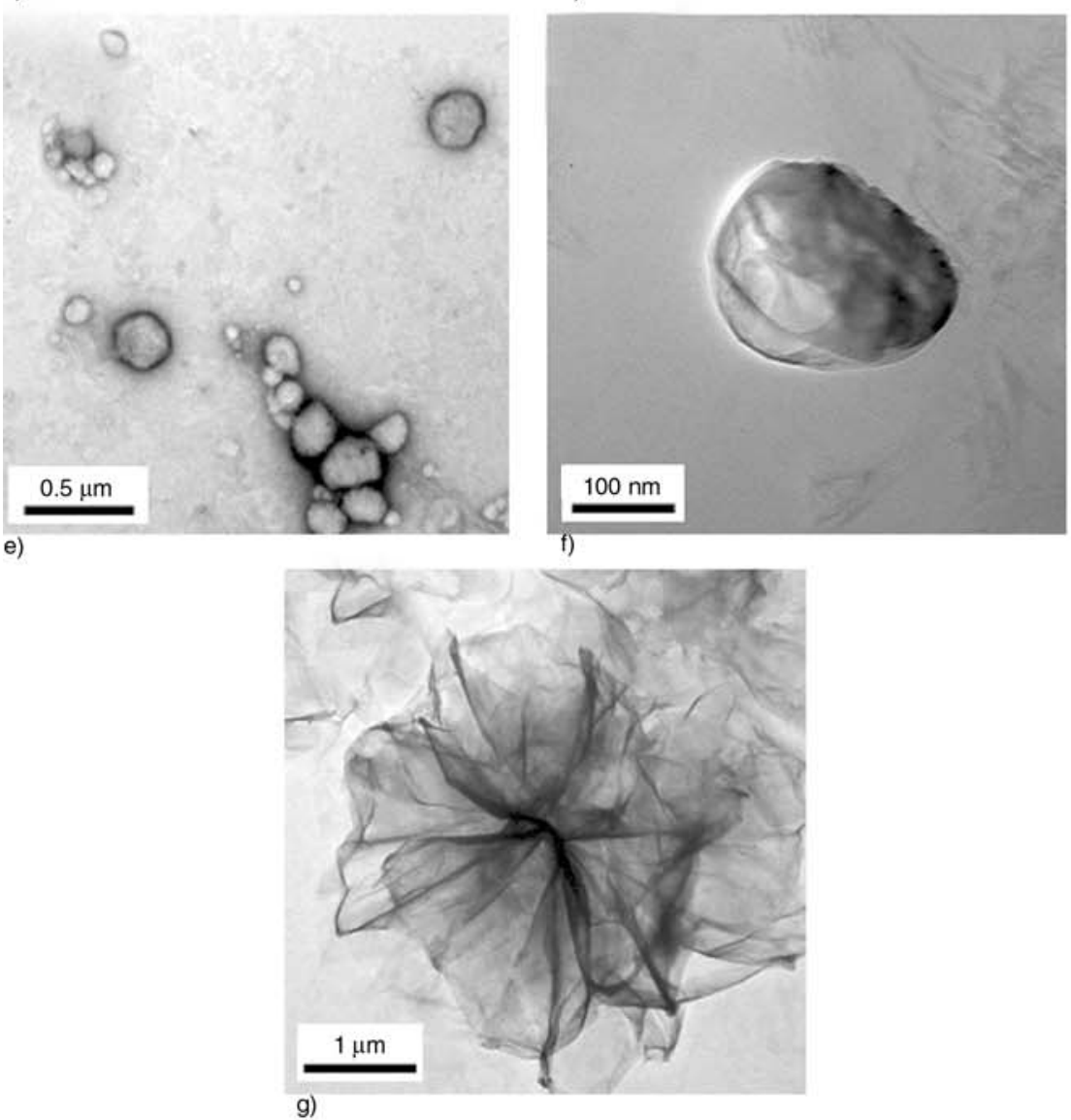

Figure 4. TEM images of structures formed by (a) $\mathrm{DEX}_{6.0 k}-b-\mathrm{PCL}_{7.5 k}$, (b) $\mathrm{DEX}_{6.0 k}-b$-PCL9.2k, (c) $\mathrm{DEX}_{3.5 k}-b$-PCL $_{7.5 k}$, (d) $\mathrm{DEX}_{3.5 k}-b$-PCL $9.2 k$, (e) $\mathrm{DEX}_{3.5 k}-b$ - $\mathrm{PCL}_{11.9 k}$, (f) $\mathrm{DEX}_{3.5 k}-b$ - $\mathrm{PCL}_{11.9 k}$ and (g) $\mathrm{DEX}_{3.5 k}-b-\mathrm{PCL}_{18.9 k}$ in aqueous media. The samples were negatively stained with phosphotungstic acid solution except for a, $\mathrm{f}$ and $\mathrm{g}$. 
$\operatorname{DEX}_{6.0 k}-b-\mathrm{PCL}_{9.2 k}\left(f_{D E X}=0.40\right)$, with corresponding diameters of $40 \pm 5$ and $30 \pm 5 \mathrm{~nm}$, respectively (Figure $4 \mathrm{~b}, 4 \mathrm{c}$ ). As the $f_{D E X}$ value further decreased to 0.28 and 0.23 , the copolymers ( $\mathrm{DEX}_{3.5 k}-b$ $\mathrm{PCL}_{9.2 k}$ and $\mathrm{DEX}_{3.5 k}-b$-PCL $_{11.9 k}$ ) self-assembled to polymersomes $120 \pm 20$ and $300 \pm 100 \mathrm{~nm}$ in diameters (Figure 4d, 4e, 4f), respectively. The interior of the aggregates has a pronouncedly lower electron density compared to the wall, suggesting vesicle morphology. The polymersomes shown in Figure $4 \mathrm{e}$ and Figure $4 \mathrm{f}$ were formed from the same diblock copolymer $\mathrm{DEX}_{3.5 \mathrm{k}}-b$ - $\mathrm{PCL}_{11.9 k}$, but differed in TEM sample preparation procedures by staining (Figure 4e) or not staining (Figure 4f) with phosphotungstic acid solution. Comparison of the two images suggests that staining may not be an essential treatment for imaging polymersomes under TEM. The wrinkles on the surface and the altered spherical shape of the particle in Figure $4 \mathrm{f}$ should be the result of polymersome shrinking due to dehydration.

Interestingly, the copolymer having larger hydrophobic block $\left(\mathrm{DEX}_{3.5 k}-b\right.$-PCL $\left.18.9 k, f_{D E X}=0.16\right)$ formed a large, flower-like structure (Figure $4 \mathrm{~g}$ ). The overall size of the 'flower' was $3.5 \pm 0.5 \mu \mathrm{m}$, considerably larger than the particulate forms assembled by less hydrophobic copolymers (Figure 4a-4f). Further increase in the hydrophobic chain length of the block copolymer $\left(\mathrm{DEX}_{3.5 k}-b-\mathrm{PCL}_{40.0 k}, f_{D E X}=0.08\right)$ lead to large, insoluble, and irregular particles (image not shown). It appeared that they were precipitated copolymers because the hydrophilicity was too low for the diblock copolymer to form stable aggregates in water.

For the observation of the flower-like structure formed by $\mathrm{DEX}_{3.5 k}-b$ - $\mathrm{PCL}_{18.9 k}$ at $f_{D E X}=0.16$, we speculate that they may be giant polymersomes by nature. This speculation was examined by loading a hydrophobic fluorescent dye, Nile red, into selfassembled solution of $\mathrm{DEX}_{3.5 k}-b$ - $\mathrm{PCL}_{18.9 k}$, followed by observation under a fluorescent microscope (FM) without dehydration. The results, as shown in Figure 5, indicated that the block copolymer formed large polymersomes with diameters around $5.4 \pm 1.2 \mu \mathrm{m}$, supportive to the speculation that giant polymersomes were the precursor of the flower-like structure observed under TEM (Figure $4 \mathrm{~g}$ ). When a hydrated polymersome was dehydrated, its overall shape should be collapsed and rumpled to give a reduced size. In addition, Nile red

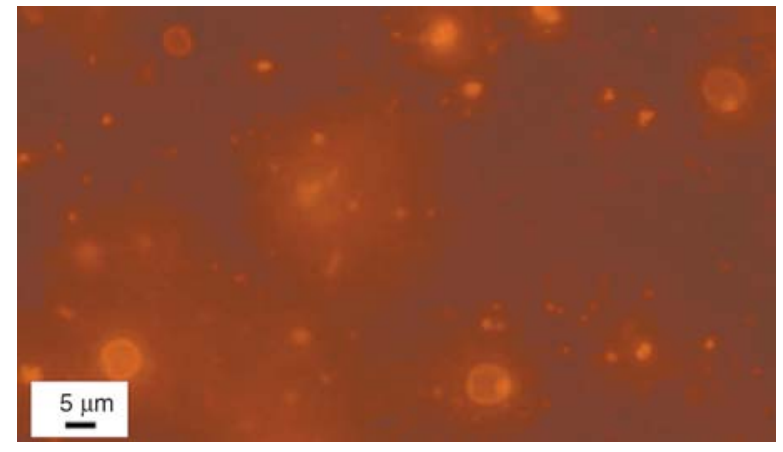

Figure 5. FM image of polymersomes formed by $\mathrm{DEX}_{3.5 k^{-}}$ $b$ - $\mathrm{PCL}_{18.9 k}$ incorporated with nile red in aqueous media

was added to aggregates formed from $\mathrm{DEX}_{3.5 k}-b$ PCL $9.2 k$ and $\mathrm{DEX}_{3.5 k}-b$-PCL $11.9 k$, but no giant polymersomes were identified under FM.

$\mathrm{DEX}_{3.5 k}-b-\mathrm{PCL}_{18.9 k}$ at $f_{D E X}=0.16$ can form polymersomes, which is out of the range of $0.25-0.42$ and does not correspond to the theory of Discher. But it is in agreement with the reports of Houga, et al. [26] that polymersomes can be prepared by DEX-b-PS of $f_{D E X}=0.08$. Due to the rod conformation of dextran with molecular weight below $2000 \mathrm{~g} \cdot \mathrm{mol}^{-1}$ [42] and the dextran T3.5 we used, most $\mathrm{DEX}_{3.5 k}$-b-PCL probably exhibit rod-coil conformation. Therefore, these results suggest that the rod-coil type diblock copolymers can form polymersomes at lower $f_{D E X}$.

As shown in Table 2, PDI of these copolymers ranges between 1.74 and 2.12. Although most amphiphilic block copolymers reported in literatures were of low polydispersities (i.e. PDI $<1.2$ ) for studying their self-assembly behaviors $[4,7,8$, 43], our work indicate that a relatively high polydispersity does not preclude their efficient selfassembly into different morphologies. However, it should be pointed out that the PDI of hydrophilic block can affect the size of aggregates [44-46]. Previous investigations reported by Choucair et al. [44], who studied the influencing factors of poly(acrylic acid)-block-polystyrene (PAA- $b$-PS) vesicle size, suggested that increasing the PDI of copolymer favor the formation of smaller vesicles by preferential segregation of shorter hydrophilic chains (e.g. PAA) to the interior surface of the vesicle and longer chains to the exterior surface.

The size distributions of the diblock copolymer assemblies were also measured by DLS. Each DLS curve was analyzed by the Log Normal method, which featured as a population peak indicating the 
Table 3. The self-assembly structures formed of diblock copolymers in aqueous solution and their diameters

\begin{tabular}{|c|c|c|c|}
\hline Polymer sample & Diameter $^{\mathrm{a}}[\mathrm{nm}]$ & Diameter $^{b}[\mathrm{~nm}]$ & Structure $^{c}$ \\
\hline $\mathrm{DEX}_{6.0 k}-b-\mathrm{PCL}_{7.5 k}$ & $45.3 \pm 2.7$ & $25 \pm 5$ & Spherical micelle \\
\hline $\mathrm{DEX}_{6.0 k}-b-\mathrm{PCL}_{9.2 k}$ & $49.0 \pm 3.6$ & $30 \pm 5$ & Spherical micelle and rod-like micelle \\
\hline $\mathrm{DEX}_{3.5 k}-b-\mathrm{PCL}_{7.5 k}$ & $75.9 \pm 8.3$ & $40 \pm 5$ & Spherical micelle \\
\hline $\mathrm{DEX}_{3.5 k-b-\mathrm{PCL}_{9.2 k}}$ & $195.9 \pm 15.2$ & $120 \pm 20$ & Polymersome \\
\hline $\mathrm{DEX}_{3.5 k-b-\mathrm{PCL}_{11.9 k}}$ & $381.3 \pm 32.7$ & $300 \pm 100$ & Polymersome \\
\hline $\mathrm{DEX}_{3.5 k-b-\mathrm{PCL}_{18.9 k}}$ & $5400 \pm 1200^{d}$ & $3500 \pm 500$ & Flower-like structure (Large polymersomed) \\
\hline
\end{tabular}

aDiameter of self-assembly structure was measured by DLS;

bDiameter of self-assembly structure was measured by TEM; cSelf-assembly structure was observed by TEM;

dThe morphology and diameter of self-assembly structure of $\mathrm{DEX}_{3.5 k}-b$ - $\mathrm{PCL}_{18.9 k}$ were determined by FM

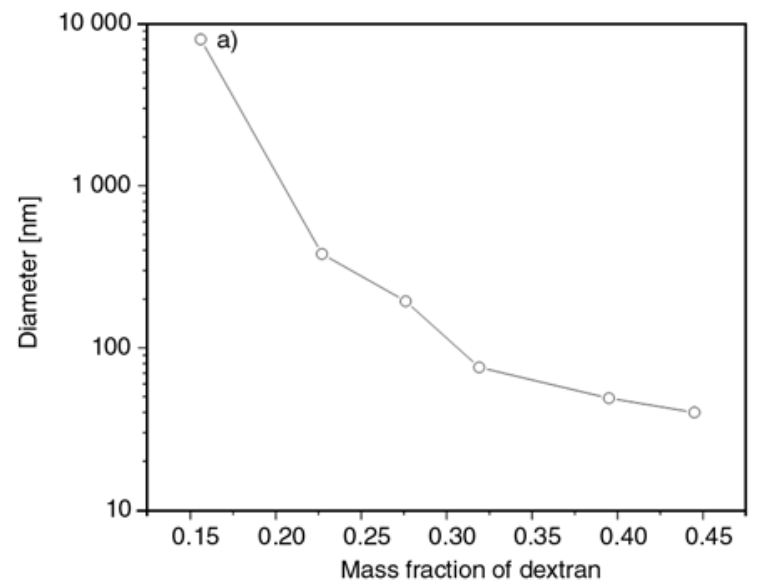

Figure 6. Plot of aggregate sizes determined by DLS vs. $f_{D E X}$ of DEX- $b$-PCL diblock copolymers in

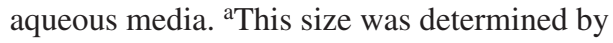
FM.

mean diameter. Table 3 shows the size distributions of the self-assembled aggregates ranged from 45.3 to $381.3 \mathrm{~nm}$. The particle sizes of diblock copolymer assemblies were plotted against $f_{D E X}$ of the copolymers in Figure 6, which shows a reversed correlation between the two factors. Table 3 lists the particle sizes and morphological forms of the assemblies of various DEX- $b$-PCL copolymers. In addition, the particle sizes measured by DLS were larger than those measured by TEM for each selfassembled aggregate, which can be attributed to the dehydration shrinkage of the particles during the TEM sample preparation.

\section{Conclusions}

Dextran and poly( $\varepsilon$-caprolactone) were conjugated together to prepare DEX- $b$-PCL diblock copolymer by aza-Michael addition under a mild condition. In order to achieve the end-to-end diblock conjugation, both DEX and PCL blocks were functionalized by modifying their terminal groups. Diblock copolymer, DEX- $b$-PCL, may self-assemble into particles of various morphological forms as a function of mass fraction of its hydrophilic block $\left(f_{D E X}\right)$. As $f_{D E X}$ decrease from 0.45 to 0.16 , the copolymer assembled to spherical micelles, worm-like micelles, small polymersomes and giant polymersomes accordingly.

\section{Acknowledgements}

We thank the Analytical and Measured Center of Shanghai Jiao Tong University for technical support. This study was financially supported by the BioPharm Solutions, Inc., and partially supported by National Grand New Drug Program (No. 2009ZX09310-007).

\section{References}

[1] Su W., Han K., Luo Y., Wang Z., Li Y., Zhang Q.: Formation and photoresponsive properties of giant microvesicles assembled from azobenzene-containing amphiphilic diblock copolymers. Macromolecular Chemistry and Physics, 208, 955-963 (2007). DOI: $\underline{10.1002 / \mathrm{macp} .200600628}$

[2] Zhu Y. J., Tan Y. B., Du X.: Preparation and selfassembly behavior of polystyrene-block-poly (dimethylaminoethyl methacrylate) amphiphilic block copolymer using atom transfer radical polymerization. Express Polymer Letters, 2, 214-225 (2008). DOI: $10.3144 /$ expresspolymlett.2008.26

[3] Lu X. J., Meng L. Z., Zhong X. X.: Novel fluorescent amphiphilic block copolymers: Photophysics behavior and interactions with DNA. Express Polymer Letters, 1, 356-363 (2007).

DOI: $10.3144 /$ expresspolymlett.2007.50

[4] Ghoroghchian P. P., Li G., Levine D. H., Davis K. P., Bates F. S., Hammer D. A., Therien M. J.: Bioresorbable vesicles formed through spontaneous selfassembly of amphiphilic poly(ethylene oxide)-blockpolycaprolactone. Macromolecules, 39, 1673-1675 (2006).

DOI: $\underline{10.1021 / \mathrm{ma} 0519009}$ 
[5] Geng Y., Ahmed F., Bhasin N., Discher D. E.: Visualizing worm micelle dynamics and phase transitions of a charged diblock copolymer in water. Journal of Physical Chemistry B, 109, 3772-3779 (2005). DOI: $10.1021 / \mathrm{jp} 0459559$

[6] Discher B. M., Won Y-Y., Ege D. S., Lee J-C., Bates F. S., Discher D. E., Hammer D. A.: Polymersomes: Tough vesicles made from diblock copolymers. Science, 284, 1143-1146 (1999).

DOI: $10.1126 /$ science.284.5417.1143

[7] Liu F., Eisenberg A.: Preparation and pH triggered inversion of vesicles from poly(acrylic acid)-blockpolystyrene-block-poly(4-vinyl pyridine). Journal of the American Chemical Society, 125, 15059-15064 (2003).

DOI: $10.1021 / \mathrm{ja} 038142 \mathrm{r}$

[8] Schmitz C., Mourran A., Keul H., Möller M.: Synthesis and association behaviour of linear block copolymers with different microstructures but the same composition. Macromolecular Chemistry and Physics, 209, 1859-1871 (2008). DOI: $10.1002 / \mathrm{macp} .200800205$

[9] Christian D. A., Cai S., Bowen D. M., Kim Y., Pajerowski J. D., Discher D. E.: Polymersome carriers: From self-assembly to siRNA and protein therapeutics. European Journal of Pharmaceutics and Biopharmaceutics, 71, 463-474 (2009).

DOI: $10.1016 /$ j.ejpb.2008.09.025

[10] Zhou W., Meng F., Engbers G. H. M., Feijen J.: Biodegradable polymersomes for targeted ultrasound imaging. Journal of Controlled Release, 116, e62-e64 (2006).

DOI: $10.1016 /$ j.jconrel.2006.09.051

[11] Discher D. E., Ahmed F.: Polymersomes. Annual Review of Biomedical Engineering, 8, 323-341 (2006).

DOI: 10.1146/annurev.bioeng.8.061505.095838

[12] Pitsikalis M., Woodward J., Mays J. W., Hadjichristidis N.: Micellization of model graft copolymers in dilute solution. Macromolecules, 30, 5384-5389 (1997). DOI: $\underline{10.1021 / \mathrm{ma} 970428 \mathrm{r}}$

[13] Rodríguez-Hernández J., Chécot F., Gnanou Y., Lecommandoux S.: Toward 'smart' nano-objects by self-assembly of block copolymers in solution. Progress in Polymer Science, 30, 691-724 (2005). DOI: $10.1016 /$ j.progpolymsci.2005.04.002

[14] Ahmed F., Discher D. E.: Self-porating polymersomes of PEG-PLA and PEG-PCL: Hydrolysis-triggered controlled release vesicles. Journal of Controlled Release, 96, 37-53 (2004).

DOI: $10.1016 /$ j.jconrel.2003.12.021

[15] Meng F., Hiemstra C., Engbers G. H. M., Feijen J.: Biodegradable polymersomes. Macromolecules, 36, 3004-3006 (2003). DOI: $10.1021 / \mathrm{ma} 034040+$
[16] Zhou W., Feijen J.: Biodegradable polymersomes for controlled drug release. Journal of Controlled Release, 132, e35-e36 (2008).

DOI: $10.1016 /$ j.jconrel.2008.09.022

[17] Lin J. J., Silas J. A., Bermudez H., Milam V. T., Bates F. S., Hammer D. A.: The effect of polymer chain length and surface density on the adhesiveness of functionalized polymersomes. Langmuir, 20, 54935500 (2004).

DOI: $10.1021 / 1 \mathrm{a} 036417 \mathrm{a}$

[18] Kingshott P., Thissen H., Griesser H.: Effects of cloud-point grafting, chain length, and density of PEG layers on competitive adsorption of ocular proteins. Biomaterials, 23, 2043-2056 (2002). DOI: $\underline{10.1016 / \mathrm{S} 0142-9612(01) 00334-9}$

[19] McPherson T., Kidane A., Szleifer I., Park K.: Prevention of protein adsorption by tethered poly(ethylene oxide) layers: Experiments and single-chain meanfield analysis. Langmuir, 14, 176-186 (1998). DOI: $\underline{10.1021 / 1 a 9706781}$

[20] Cismaru L., Hamaide T., Popa M.: Itaconic anhydride based amphiphilic copolymers: Synthesis, characterization and stabilization of carboxyl functionalized, PEGylated nanoparticles. European Polymer Journal, 43, 4843-4851 (2007). DOI: $10.1016 /$ j.eurpolymj.2007.09.023

[21] Lee J. C-M., Bermudez H., Discher B. M., Sheehan M. A., Won Y-Y., Bates F. S., Discher D. E.: Preparation, stability, and in vitro performance of vesicles made with diblock copolymers. Biotechnology and Bioengineering, 73, 135-145 (2001). DOI: $\underline{10.1002 / \mathrm{bit} .1045}$

[22] Heinze T., Liebert T., Heublein B., Horning S.: Functional polymers based on dextran. Advances in Polymer Science, 205, 199-291 (2006).

DOI: $\underline{10.1007 / 12 \quad 100}$

[23] Diamond A., Hsu J.: Protein partitioning in PEG/dextran aqueous two-phase systems. AICHE Journal, 36, 1017-1024 (1990). DOI: 10.1002/aic.690360707

[24] Lu Y., Chen S.: Micro and nano-fabrication of biodegradable polymers for drug delivery. Advanced Drug Delivery Reviews, 56, 1621-1633 (2004). DOI: 10.1016/j.addr.2004.05.002

[25] Goldberg D.: A review of the biodegradability and utility of poly(caprolactone). Journal of Polymers and the Environment, 3, 61-67 (1995). DOI: $10.1007 / \mathrm{BF} 02067481$

[26] Houga C., Giermanska J., Lecommandoux S., Borsali R., Taton D., Gnanou Y., Le Meins J-F.: Micelles and polymersomes obtained by self-assembly of dextran and polystyrene based block copolymers. Biomacromolecules, 10, 32-40 (2009). DOI: $10.1021 / \mathrm{bm} 800778 \mathrm{n}$ 
[27] Liu J-Y., Zhang L-M.: Preparation of a polysaccharide-polyester diblock copolymer and its micellar characteristics. Carbohydrate Polymers, 69, 196-201 (2007).

DOI: 10.1016/j.carbpol.2006.09.009

[28] Schatz C., Louguet S., Le Meins J-F., Lecommandoux S.: Polysaccharide-block-polypeptide copolymer vesicles: Towards synthetic viral capsids. Angewandte Chemie International Edition, 48, 2572-2575 (2009). DOI: $10.1002 / a n i e .200805895$

[29] Hernandez O. S., Soliman G. M., Winnik F. M.: Synthesis, reactivity, and $\mathrm{pH}$-responsive assembly of new double hydrophilic block copolymers of carboxymethyldextran and poly(ethylene glycol). Polymer, 48, 921-930 (2007).

DOI: $10.1016 /$ j.polymer.2006.12.036

[30] Yang Y. L., Kataoka K., Winnik F. M.: Synthesis of diblock copolymers consisting of hyaluronan and poly(2-ethyl-2-oxazoline). Macromolecules, 38, $2043-$ 2046 (2005).

DOI: $10.1021 / \mathrm{ma} 047439 \mathrm{~m}$

[31] Sun H., Guo B., Li X., Cheng R., Meng F., Liu H., Zhong Z.: Shell-sheddable micelles based on dextranSS-poly( $\varepsilon$-caprolactone) diblock copolymer for efficient intracellular release of doxorubicin. Biomacromolecules, 11, 848-854 (2010).

DOI: $10.1021 / \mathrm{bm} 1001069$

[32] Bosker W. T. E., Ágoston K., Stuart M. A. C., Norde W., Timmermans J. W., Slaghek T. M.: Synthesis and interfacial behavior of polystyrene-polysaccharide diblock copolymers. Macromolecules, 36, 1982-1987 (2003).

DOI: $10.1021 / \mathrm{ma} 020925 \mathrm{u}$

[33] Loos K., Stadler R.: Synthesis of amylose-block-polystyrene rod-coil block copolymers. Macromolecules, 30, 7641-7643 (1997). DOI: $\underline{10.1021 / \mathrm{ma} 971022 \mathrm{~h}}$

[34] Xu N., Lu F-Z., Du F-S., Li Z-C.: Synthesis of saccharide-terminated poly( $\varepsilon$-caprolactone) via Michael addition and 'click' chemistry. Macromolecular Chemistry and Physics, 208, 730-738 (2007). DOI: $\underline{10.1002 / \mathrm{macp} .200600533}$

[35] Kakuchi T., Narumi A., Miura Y., Matsuya S., Sugimoto N., Satoh T., Kaga H.: Glycoconjugated polymer. 4. Synthesis and aggregation property of welldefined end-functionalized polystyrene with $\beta$ cyclodextrin. Macromolecules, 36, 3909-3913 (2003). DOI: $\underline{10.1021 / \mathrm{ma0} 21295 \mathrm{z}}$

[36] Moreau M.: Method for the reductive amination of polysaccharides. U.S. Patent 6596861 B1, USA (2003).
[37] Mather B. D., Viswanathan K., Miller K. M., Long T. E.: Michael addition reactions in macromolecular design for emerging technologies. Progress in Polymer Science, 31, 487-531 (2006). DOI: $10.1016 /$ j.progpolymsci.2006.03.001

[38] Xu N., Du F-S., Li Z-C.: Synthesis of poly(L-lysine)graft-polyesters through Michael addition and their self-assemblies in aqueous solutions. Journal of Polymer Science Part A: Polymer Chemistry, 45, 1889 1898 (2007).

DOI: $10.1002 /$ pola.21949

[39] Mantovani G., Lecolley F., Tao L., Haddleton D. M., Clerx J., Cornelissen J., Velonia K.: Design and synthesis of $\mathrm{N}$-maleimido-functionalized hydrophilic polymers via copper-mediated living radical polymerization: A suitable alternative to PEGylation chemistry. Journal of the American Chemical Society, 127, 2966-2973 (2005). DOI: $10.1021 / \mathrm{ja} 0430999$

[40] Zentz F., Valla A., Le Guillou R., Labia R., Mathot AG., Sirot D.: Synthesis and antimicrobial activities of $N$-substituted imides. Il Farmaco, 57, 421-426 (2002). DOI: $\underline{10.1016 / \mathrm{S} 0014-827 \mathrm{X}(02) 01217-\mathrm{X}}$

[41] Borch R. F., Bernstein M. D., Durst H. D.: Cyanohydridoborate anion as a selective reducing agent. Journal of the American Chemical Society, 93, 2897-2904 (1971).

DOI: $10.1021 / \mathrm{ja} 00741 \mathrm{a} 013$

[42] Gekko K.: Solution properties of dextran and its ionic derivatives. in 'Solution properties of polysaccharides' (ed.: Brant D. A.) ACS Publications, Washington, Vol 150, 415-438 (1981).

DOI: $10.1021 / \mathrm{bk}-1981-0150 . c h 029$

[43] Sun J., Shi Q., Chen X., Guo J., Jing X.: Self-assembly of a hydrophobic polypeptide containing a short hydrophilic middle segment: Vesicles to large compound micelles. Macromolecular Chemistry and Physics, 209, 1129-1136 (2008).

DOI: $\underline{10.1002 / \mathrm{macp} .200800018}$

[44] Choucair A., Lavigueur C., Eisenberg A.: Polystyrene- $b$-poly(acrylic acid) vesicle size control using solution properties and hydrophilic block length. Langmuir, 20, 3894-3900 (2004). DOI: $\underline{10.1021 / \mathrm{la} 035924 \mathrm{p}}$

[45] Terreau O., Luo L., Eisenberg A.: Effect of poly (acrylic acid) block length distribution on polystyrene$b$-poly(acrylic acid) aggregates in solution. 1. Vesicles. Langmuir, 19, 5601-5607 (2003). DOI: $10.1021 / \mathrm{la} 0269715$

[46] Luo L., Eisenberg A.: Thermodynamic stabilization mechanism of block copolymer vesicles. Journal of the American Chemical Society, 123, 1012-1013 (2001). DOI: $\underline{10.1021 / \mathrm{ja} 005824 \mathrm{v}}$ 